\title{
Medication interruptions and associated factors among nurses working in pediatric unit at a selected referral hospital in Rwanda.
}

\author{
*Aimable Nkurunziza ${ }^{1,2 *}$, Geldine Chironda ${ }^{1,3}$, Godfrey Katende ${ }^{1}$, Lakshmi Rajeswaran ${ }^{1}$, \\ Emmanuel Munyaneza ${ }^{4}$, Madeleine Mukeshimana ${ }^{1}$
}

\begin{abstract}
Introduction: Interruptions have been proven to cause medication administration errors in pediatric settings. Therefore, this study assessed the medication interruptions and associated factors among nurses in a pediatric unit at a selected referral hospital in Rwanda.
\end{abstract}

Methods: A descriptive observational study was conducted among 59 nurses using a developed observational checklist. Data were entered into SPSS, version 26. Descriptive and inferential statistics were used to analyze the data. The IRB of the University of Rwanda approved the study.

Results: Among the 414 medication administrations observed, 149 (36\%) had interruptions. The main source of interruption was technical problem (14.5\%) with interruption from direct care (12\%) as the main reason. The factors associated with interruption occurrence were shift of the day, time of medication round, duration and phase of medication administration and nurse perception $(p=0.001)$, age $(p=0.046)$, educational level $(p=0.044)$ and professional experience $(p=0.031)$.

Conclusion: The existence of medication interruptions is evident with associated factors predominantly being demographics and technical. Therefore, the authors recommended that an in-service training program for nurses regarding medication administration errors. The hospital leadership should address the technical problems including availing the required materials for medication administration.

Key words: Interruptions, medication administration, pediatric, nurses, Rwanda.

\author{
*Corresponding Author \\ Aimable Nkurunziza \\ ORCID-NO: http://orcid.org/0000-0001-5052-6172 \\ Email:ankurun@uwo.ca
}

\footnotetext{
${ }^{1}$ University of Rwanda, College of Medicine and Health Sciences, School of Nursing and Midwifery, Kigali, Rwanda.

${ }^{2}$ University of Western Ontario, Faculty of Health Sciences, Arthur Labatt Family School of Nursing, London, Canada.

${ }^{3}$ University of KwaZulu-Natal, College of Health Sciences, School of Nursing and Public Health, Durban, South Africa.

${ }^{4}$ University Teaching Hospital of Kigali, Kigali, Rwanda
} 


\title{
Interruptions médicamenteuses et facteurs associés chez les infirmières travaillant dans l'unité pédiatrique d'un hôpital de référence sélectionné au Rwanda
}

\author{
*Aimable Nkurunziza ${ }^{1,2 *}$, Geldine Chironda ${ }^{1,3}$, Godfrey Katende ${ }^{1}$, Lakshmi Rajeswaran ${ }^{1}$, \\ Emmanuel Munyaneza ${ }^{4}$, Madeleine Mukeshimana ${ }^{1}$
}

\section{Résumé}

Introduction : Il a été prouvé que les interruptions provoquent des erreurs d'administration de médicaments en milieu pédiatrique. Par conséquent, cette étude a évalué les interruptions de médication et les facteurs associés chez les infirmières d'une unité de pédiatrie d'un hôpital de référence sélectionné au Rwanda.

Méthode de l'étude : Une étude observationnelle descriptive a été menée auprès de 59 infirmières à l'aide d'une liste de contrôle d'observation élaborée. Les données ont été saisies dans SPSS, 26. Des statistiques descriptives et inférentielles ont été utilisées pour analyser les données. L'IRB de l'Université du Rwanda a approuvé l'étude.

Résultats de l'étude : Parmi les 414 administrations de médicaments observées, 149 (36\%) ont subi des interruptions. La principale source d'interruption était un problème technique $(14,5 \%)$ avec l'interruption des soins directs $(12 \%)$ comme principale raison. Les facteurs associés à l'occurrence d'interruption étaient décalage de la journée, heure de la tournée de médicaments, durée et phase d'administration des médicaments et perception de l'infirmière $(p=0,001)$, âge $(p=0,046)$, niveau d'éducation $(p=0,044)$ et expérience professionnelle $(\mathrm{p}=0,031)$.

Conclusion : L'existence d'interruptions de médication est évidente avec des facteurs associés principalement démographiques et techniques. Par conséquent, les auteurs recommandent un programme de formation continue pour les infirmières concernant les erreurs d'administration de médicaments. La direction de l'hôpital devrait résoudre les problèmes techniques, notamment en mettant à disposition les matériaux requis pour l'administration des médicaments.

Mots-clés : Interruptions, administration de médicaments, pédiatrie, infirmières, Rwanda

\author{
*Corresponding Author \\ Aimable Nkurunziza \\ ORCID-NO: http://orcid.org/0000-0001-5052-6172 \\ Email:ankurun@uwo.ca
}

${ }^{1}$ College of Medicine and Health Sciences, School of Nursing and Midwifery, University of Rwanda, Kigali, Rwanda.

${ }^{2}$ Faculty of Health Sciences, Arthur Labatt Family School of Nursing, University of Western Ontario, London, Canada.

${ }^{3}$ College of Health Sciences, School of Nursing and Public Health, University of KwaZulu-Natal, Durban, South Africa.

${ }^{4}$ University Teaching Hospital of Kigali, Kigali, Rwanda.

Research Journal of Health Sciences subscribed to terms and conditions of Open Access publication. Articles are distributed under the terms of Creative Commons Licence (CC BY-NC-ND 4.0). (http://creativecommons.org/licences/by-nc-nd/4.0).

http://dx.doi.org/10.4314/rejhs.v9i4.1 


\section{INTRODUCTION}

Globally, medication errors remain a major challenge to patient safety in various health care settings (1). Annually, in the United States, one patient dies per day due to medication errors (2) thus making it the third leading cause of deaths in the country (4). Additionally, the total amount of money spent on medication errors totals up to 42 billion US\$ or $1 \%$ of the total global health expenses (3).

Medication administration is among the important steps of medication management $(6,7)$ with influencing diverse factors such as individual, environmental, systems and culture (6-9). Interruptions on the other hand are, defined as anything that can hinder or stop performance of the main task and forces attention to a new task (4), have been proven to cause numerous medication administration errors in the healthcare setting (5-8). For instance, nurses spend at least $2.5 \mathrm{~min}$ addressing other problems during medication administration leading to medication administration errors (9). Not all interruptions are disagreeable in the provision of care but some require special attention because they could result into medical errors $(10,11)$.

A systematic review conducted to assess work interruptions highlights medication administration errors as the main sequel for work interruption with nurses identified as the key players of these interruptions $(17,18)$. A study conducted by Zhao and colleagues (20), supports the notion that interruptions cause more than half (53.1\%) of the medication administration errors. Additionally, an observational study has revealed that for every 100 drug administrations, there were 57 interruptions (12). Similarly, nurses' duties during medication administration are interrupted to the extent that the nurses might spend at least $2.5 \mathrm{~min}$ managing the interruptions themselves. Additionally, the causal relationship study has identified that nurses commit errors when they are interrupted as opposed to when they are not (6). With regards to this, an intervention known as the "do not interrupt" has been identified to be most effective in the reduction of interruptions from 50 up to $34 / 100$ administrations (12).

The occurrence of numerous medication interruptions is escalating with a predominance in pediatric health care settings $(13,14)$. In Turkey, interruptions caused 61 medication administration errors in the pediatric department with mothers, physicians and nurses being noted as the primary causes (15). In pediatric units of selected referral hospitals in Rwanda, the participants $(26.8 \%)$ strongly agreed that interruptions play an important role in medication administration errors (16). Although interruptions have been identified as a major contributor to medication administration errors in Rwanda, data on the frequency and their sources are scarce. Therefore, the study aimed to assess medication interruptions that occur during medication administration and its associated factors among nurses in pediatric unit at a selected referral hospital in Rwanda.

\section{MATERIALS AND METHODS Research design}

This study was a descriptive crosssectional observational study conducted in December 2018.

\section{Research Setting}

This research was conducted in a Rwandan Referral Hospital. The hospital has been chosen because it employs more pediatric nurses and receives referred complex cases from district hospitals for high-level specialized care.

\section{Study Population}

Nurses that work in the pediatric department of the selected referral hospital in Rwanda and demonstrated the will to participate in the study were selected. However, nurses in the pediatric emergency were excluded because the department does not have the scheduled medications round. Moreover, the emergency department is used as transit to other pediatric wards within the selected referral hospital.

\section{Sample size and sampling strategy}

The pediatric department has 79 nurses including neonatology. After exclusion of neonatology and pediatric emergency department, 59 nurses consented to participate in the study. Convenience sampling was used to select study participants as they were accessible and proximal to the researcher.

\section{Data Collection Instrument}

An adapted observational checklist was used in the current study (14). It was composed of three main parts namely; 1) the general environment characteristics such as the days of the week; 2) shift of the day and time of medication round. Work interruptions characteristics such as phase of medication administration process (MAP), source, reason and effect and 3) study participants' sociodemographic characteristics such as age, gender, 
marital status, educational level, professional/nursing experience in pediatric department and nurses' perception to work interruptions to cause medication error.

\section{Operational definitions of the study instrument}

The checklist had the following explanations of some items to guide the data collectors. Interruptions were operationally defined as a break in performing a task, evidenced by cessation of a primary task, as a break is measurable task switch behavior. While, distractions were defined as breaks in attention, as evidenced by observed behavior such as responding verbally delivered through face to face conversation or a phone ring distraction.

Medication administration process (MAP) was defined as all activities undertaken by a nurse related with medication preparation, verification, administration, documentation, and clarification regards to any form or route of medications. Prescribing, transcribing, dispensing, searching/retrieving for medication were not part of this time frame in MAP. Based on these concepts, for the purpose of this study, phases of MAP were modified into three main categories: (a) pre-administration phase--consists preparation and verification of medication; (b) administration phase - delivering medication to the patient; and (c) post- administration phase - consists verification, documentation, and in-transit between one patient's medication to another patient's medication activity or an in transit between one to another's medication of the same patient.

Sources (initiators) were referred to peoples (as persons as a whole within defined characteristics), phone call/pager, or technical problem, those can visibly distract/interrupt the nurse. The secondary tasks (reasons) were explained as the WI which occurs as the intrusion of a secondary, unplanned and unscheduled task that resulted in distraction/interruption to the nurse's activity to the MAP.

\section{Data collection Procedure}

Two research assistants from the pediatric department were recruited and trained before data collection for a period of two days. Informed consents were signed 2 weeks prior to the study and thus ensured participants' awareness of the activities initiated during observation. This was indicated in the informed consent and letter of information. The data collector sat at the appropriate setting where they could observe the nurses during medication administration with ease. The data collection was conducted under supervision of the two co investigators of the study. One research assistant observed the nurse who was administering the medication at a time. Data were collected during the following shifts of medication administration: 6-8a.m, 2-4p.m and 10-11p.m. The data collection began once the nurse opened the drug to be administered and ended with the trolley being observed on activity to the MAP.

\section{Data Analysis}

Data entry and analysis were done by Microsoft Excel and Statistical Package for the Social Sciences (SPSS) version 26. Descriptive statistics were used to analyze the types of interruptions, frequency and their common sources. Multivariate analysis with Chi square and fisher exact tests were used accordingly to explore the association between the interruption and various variables thought to be influencing this occurrence. Results were presented in tables and frequencies.

Ethical Consideration: The study was approved by the Internal Review Board (IRB) from the University of Rwanda. The Ethical approval was sent to the selected referral hospital and the permission for data collection was granted. Participants were assured of their rights including self-determination, privacy and confidentiality, fair management and the right of protection against embarrassment and hurt. The code numbers of the nurses were utilized on the checklist instead of their names. Informed consent was obtained from each participant.

\section{RESULTS}

\section{Participants' socio-demographic data $(\mathrm{N}=59)$}

The majority of the study participant observed were female 56 (95\%) with predominant age group ranging from 31 to 40 years old [40(68\%)]. The majority [54 (92\%)] had an advanced diploma (A1) in Nursing with working experience [25 (42\%)] ranging from 6 to 10 years (Table 1 ).

\section{Occurrence of Work Interruptions}

A total of 414 medication administrations were observed with149 (36\%) sessions interrupted. The occurrence of interruptions were due to distractions [105(25.4\%)], taking short breaks [38 (9.2\%)] 
and abandonment [6(1.4\%)].

\section{Sources of Work Interruptions}

The most common source of interruption was patient related [38(9.2\%)], followed by selfinitiated causes [24(5.8\%)]. See Table 2

\section{Reason for Work Interruptions}

In this study, table 3 reveals that the main reasons for work interruptions were direct care [50(12.1\%)], indirect care [41(9.9\%)], social [25(6\%)], professional discussion [21(5.1\%)], failure resolution $[16(3.9 \%)]$, clerical $[5(1.2 \%)]$, administrative [3(0.7\%)] and teaching [2(.5\%)].

The factors associated with interruption occurrence were shift of the day, time of medication round, duration and phase of medication administration and nurse perception $(\mathrm{p}=0.001)$, age $(\mathrm{p}=0.046)$, educational level $(\mathrm{p}=$ $0.044)$ and professional experience $(p=0.031)$ (Table 3).

\section{Multivariate analysis}

In (Table 4), the multivariate analysis shows that shift of the day and duration of interruption are the only two independent variables which have a protective effect on the interruption occurrence meaning more interruptions occurred during day shift.

\section{DISCUSSION}

Interruptions during medication administration continue to be a major problem in pediatric healthcare settings. Despite some established interventions, interruptions are still ranked among the top causes of medication administration errors (7). Several observational studies have discovered that over half of the medication administered by nurses are interrupted (17-19). The results from the current study are in consistence with the study which has been conducted by Biron and colleagues (23). However, a recent study has highlighted that $94.51 \%$ of medication administered in pediatric settings were interrupted (20).

The most common source of interruption was technical problem (14.5\%), which in context is defined as missing medication, material, equipment including emergency situations, IVline failure and external noises that results in distraction, interruption and abandoning the nurse's activity. These results corroborate with other studies which identified insufficient materials as an important leading cause of interruptions during medication administration
$(21,22)$. Further results revealed the main sources of interruptions from healthcare professionals (23-25) while other studies indicated patient related as the main source $(23,26)$.

The main reason for interruption was direct care $(12 \%)$ as a result of either admitting, reviewing or escorting a patient, performing or assisting other urgent nursing procedures, and communicating with relatives about care. These results confirms other findings which highlighted pediatric nurses getting interrupted when dealing with caregivers, especially in situations when they are inquiring about any issues relating to their children during medication administration(15).

It is evident that shift of day, time of medication round, duration of medication administration, phase, age, marital status, education level, professional experience and nurses' perception of work interruption risks were factors associated with occurrence of medication interruptions. Some of these factors are consistent with the study done in Ethiopia (14). However, shift of the day and duration of interruption are the only independent variables which have a protective effect on the interruption occurrence. Similarly, a study conducted by Relihan and colleagues (25), discovered a significant difference between occurrence of interruptions between the day and night shifts.

\section{Strengths and Limitations}

This research used an observational method of collecting data which is appropriate for observing the clinical practice of nurses, not perceived. Two weeks prior to the data collection phase, informed consents were signed and study objectives were explained to the study participants while socio-demographic data were also collected after observation to further minimize bias The study used one department of pediatric ward which had a limited number of nurses in the study setting. Again, the study was carried out in one hospital, therefore, cannot be generalized to other pediatric health care settings in Rwanda. Nurses were conveniently selected, meaning those that did not participate in the study might have kept additional practices, which were not identified by the consenting study participants, hence the ossibility of information bias.

\section{CONCLUSION}

A significant number of interruptions during medication administration in pediatric units were observed with technical problem as the 
main source. Several factors such as shift of day, time of medication round, duration of medication administration, phase, age, marital status and education level were found to be associated with the occurrence of interruptions.

Recommendations: Therefore, the clinical settings should develop interventions to minimize interruptions during medication administration such as reducing technical problems by availing medication administration materials and continuous training to nurses. The institutions should allocate adequate specific numbers of nurses depending on the shifts.

Acknowledgements: The authors would like to than the University Teaching Hospital of Kigali and the study participants

Conflicts of interests: The authors declared that they have no conflicts of interest

Authors' contributions: Aimable Nkurunziza (AN), Geldine Chironda (GC), Gedfrey Katende (GK), Lakshmi Rajeswaran (LR) and Madeleine Mukeshimana (MM). conceptualized the ideas and wrote the proposal. AN, GC and Emmanuel Munyaneza (EM) participated in data collection, analysis and interpretation. All authors participated in manuscript review, read and approved the final draft of manuscript.

\section{REFERENCES}

1. WHO. Patient Safety: Making Health Care Safer. 2017.

2. U.S. Food and Drug Administration. Medication Error Reports. FDA. 2016.p. 1.

3. WHO. WHO launches global effort to halve medication-related errors in 5 years. WHO. 2017.p. 1.

4. Institute for safe medication practices. Side tracks on the safety express. Interruptions lead to errors and unfinished... Wait, what was I doing? 2012.

5. Bergqvist M, Karlsson EA, Björkstén KS, Ulfvarson J. Medication Errors by Nurses in Sweden-Classification and Contributing factors. Open Access Sci Reports. 2012;1(11):1-4.

6. Prakash V, Koczmara C, Savage P, Trip K, Stewart J, Mccurdie T, et al. Mitigating errors caused by interruptions during medication verification and administration? interventions in a simulated ambulatory chemotherapy setting. 2014; (June):1-10.

7. Wondmieneh A, Alemu W, Tadele N, Demis A. Medication administration errors and contributing factors among nurses? a cross sectional study in tertiary hospitals, Addis. BMC
Nurs. 2020;19(4):1-9.

8. Nkurunziza A, Chironda G, Mukeshimana M, Uwamahoro MC, Umwangange ML, Ngendaayo F. Factors Contributing to Medication Administration Errors and Barriers to Self- Reporting among Nurses? A Review of Literature. Rwanda J Med Heal Sci. 2019;2(3):294-303.

9. Johnson M, Sanchez P, Langdon R, Manias E, Levett-Jones T, Weidemann G, et al. The impact of interruptions on medication errors in hospitals: an observational study of nurses. J Nurs Manag [Internet]. 2017;25(7):498-507. A v a i l a b l e f $\mathrm{r} \mathrm{o} \mathrm{m} \mathrm{:}$ http://www.ncbi.nlm.nih.gov/pubmed/2854435 1

10. Rivera JA, Karsh B-T. Interruptions and Distractions in Healthcare: Review and Reappraisal. Qual Saf Heal Care. 2011;19(4):304-12.

11. Grissinger M. Sidetracks on the safety express: interruptions lead to errors and ... wait, what was I doing? P T [Internet]. 2015;40(3):145-90.

12. Westbrook JI, Li L, Hooper TD, Raban MZ, Middleton S, Lehnbom EC. Effectiveness of a Do not interrupt' bundled intervention to reduce interruptions during medication administration: A cluster randomised controlled feasibility study. BMJ Qual Saf. 2017;26(9):734-42.

13. Monteiro C, Avelar MFA, Pedreira GM da L. Interruptions of nurses ' activities and patient safety? an integrative review. Rev Latino-Am Enferm. 2015;23(1):169-79.

14. Getnet MA, Bifftu BB. Work Interruption Experienced by Nurses during Medication Administration Process and Associated Factors, Northwest Ethiopia. Nurs Res Pract. 2017;2017(1-7).

15. Özkan S, Kocaman G, Öztürk C. Interruptions During Pediatric Medication Preparation and Administration. J Pediatr Res. 2016;3(2):104-8.

16. Nkurunziza A, Chironda G, Mukeshimana M. Perceived contributory factors to medication administration errors ( MAEs ) and barriers to self-reporting among nurses working in paediatric units of selected referral hospitals in Rwanda. Int J Res Med Sci. 2018;6(2):401-7.

17. Cooper HC, Tupper R, Holm K. Interruptions during medication administration: A descriptive study. Medsurg Nurs. 2016;25(3):186-91.

18. Kreckler S, Catchpole K, Bottomley M, Handa A, Mcculloch P. Interruptions during drug rounds? an observational study. Br J Nurs. 2008; 17(21):111-4.

19. Westbrook JI, Woods A, Rob MI, Dunsmuir WTM, Day RO. Association of Interruptions With an Increased Risk and Severity of Medication Administration Errors. Arch Intern Med. 2010;170(8):683-90.

20. Zhao J, Zhang X, Wang W, Zeng Y. Interruptions experienced by nurses during pediatric medication administration in China? An 
observational study. J Spec Pediatr Nurs 2019;24(e12265):1-6.

21. Duruk N, Zenchir G, Eser I. Interruption of the medication preparation process and an examination of factors causing interruptions. J Nurs Manag 2016. 2016;24:376-83.

22. Aguirre T, Wilhelm S, Backer S, Schoeneman S, Koehler A. Interruptions in a Rural Hospital and Evaluation of a Red Light Intervention. Online J Rural Nurs Heal Care, . 2015;2:49-62.

23. Biron AD, Loiselle CG. Characteristics of Work Interruptions During Medication Administration. J Nurs Scholarsh. 2009;41(4):330-6.
24. Smeulers M, Hoekstra M, Dijk E Van, Overkamp F, Vermeulen H. Interruptions during nurses' medication administration rounds. Nurs Reports. 2013;3(3):e4.

25. Relihan E, Brien VO, Hara SO, Silke B. The impact of a set of interventions to reduce interruptions and distractions to nurses during medication administration. Qual Saf Heal Care. 2010;19(52):2010.

26. Hedberg B, Larsson U. Environmental elements affecting the decision-making process in nursing practice. Clin Nurs Issues. 2004;13 (1997)

How to cite this article:

Aimable Nkurunziza, Geldine Chironda, Godfrey Katende, Lakshmi Rajeswaran, Emmanuel Munyaneza, Madeleine Mukeshimana. Medication interruptions and associated factors among nurses working in pediatric unit at a selected referral hospital in Rwanda. Research Journal of Health Sciences, 2021, 9(4):320-329 
Table1: Scio-demographic data of the study participants and their perceived risk of Work Interruptions $(\mathbf{N}=59)$

\begin{tabular}{|c|c|c|c|}
\hline Parameters & & Frequency & Percent \\
\hline \multicolumn{4}{|l|}{ Gender } \\
\hline & Male & 3 & 5 \\
\hline & Female & 56 & 95 \\
\hline \multicolumn{4}{|l|}{ Age } \\
\hline & $<26$ years & 2 & 3 \\
\hline & 26-30 years & 7 & 12 \\
\hline & $31-40$ years & 40 & 68 \\
\hline & $>40$ Years & 10 & 17 \\
\hline \multicolumn{4}{|c|}{ Marital status } \\
\hline & Single & 9 & 15 \\
\hline & Married & 46 & 78 \\
\hline & Widower & 2 & 3 \\
\hline & Divorced & 2 & 3 \\
\hline \multicolumn{4}{|c|}{ Education status (in nursing) } \\
\hline & Diploma A1 & 54 & 92 \\
\hline & Bachelor's degree & 3 & 5 \\
\hline & Masters' degree & 2 & 3 \\
\hline \multicolumn{4}{|c|}{ Professional experience( in nursing) } \\
\hline & $<6$ years & 22 & 37 \\
\hline & $6-10$ years & 25 & 42 \\
\hline & $>10$ years & 12 & \\
\hline
\end{tabular}

Table 2. Sources of interruptions $(\mathrm{N}=414)$

\begin{tabular}{lll}
\hline Source of interruption & Frequency & Percentages \\
\hline No interruption & 264 & 63.8 \\
Self-initiated & 24 & 5.8 \\
Patient & 38 & 9.2 \\
Health Professional & 16 & 3.9 \\
Visitor & 5 & 1.2 \\
Supportive staff & 3 & 0.7 \\
Phone Call & 3 & 0.7 \\
Student & 1 & 0.2 \\
Technical problem & 60 & 14.5 \\
Total & 414 & 100.0 \\
\hline
\end{tabular}

Table 3. The reasons for Work Interruptions $(\mathrm{N}=414)$

\begin{tabular}{lll}
\hline Reasons for interruptions & Frequency & Percentages \\
\hline No interruption & 264 & 63.8 \\
Direct care & 50 & 12.1 \\
Indirect care & 41 & 9.9 \\
Failure resolution & 16 & 3.9 \\
Professional discussion & 21 & 5.1 \\
Clerical & 5 & 1.2 \\
Teaching & 2 & .5 \\
Administrative & 3 & .7 \\
Social & 25 & 6.0 \\
Total & 414 & 100.0 \\
\hline
\end{tabular}


Table. 3. Bivariate analysis of the factors associated with interruption occurrence

\begin{tabular}{|c|c|c|c|}
\hline \multirow[t]{2}{*}{ Variables } & \multicolumn{2}{|c|}{ Occurrence of interruption } & \multirow[t]{2}{*}{ P value } \\
\hline & Yes & No & \\
\hline \multicolumn{4}{|l|}{ Working days } \\
\hline Week days & $136(91.3 \%)$ & $253(95.5 \%)$ & 0.085 \\
\hline Weekends & $13(8.3 \%)$ & $12(4.5 \%)$ & \\
\hline Total & $149(100 \%)$ & $265(100 \%)$ & \\
\hline \multicolumn{4}{|l|}{ Shift of day } \\
\hline Day shift & $109(73.2 \%)$ & $108(40.8 \%)$ & $<0.001$ \\
\hline Night & $40(26.8 \%)$ & $157(59.2 \%)$ & \\
\hline Total & $149(100 \%)$ & $256(100 \%)$ & \\
\hline \multicolumn{4}{|c|}{ Time of medication round } \\
\hline $6 \mathrm{AM}$ & $22(14.8 \%)$ & $54(20.4 \%)$ & $<0.001$ \\
\hline $2 \mathrm{PM}$ & $69(46.3 \%)$ & $59(22.3 \%)$ & \\
\hline $6 \mathrm{PM}$ & $40(26.8 \%)$ & $48(18.1 \%)$ & \\
\hline $10 \mathrm{PM}$ & $18(12.1 \%)$ & $104(39.2 \%)$ & \\
\hline Total & $149(100 \%)$ & $265(100 \%)$ & \\
\hline \multicolumn{4}{|c|}{ Duration of medication administration } \\
\hline $0-5$ hours & $134(89.9 \%)$ & $2(0.8 \%)$ & $<0.001$ \\
\hline $6-10$ hours & $12(8.1 \%)$ & $0(0.0 \%)$ & \\
\hline 11-15 hours & $2(1.3 \%)$ & $0(0.0 \%)$ & \\
\hline$>16$ hours & $1(0.7 \%)$ & $0(0.0 \%)$ & \\
\hline Total & $149(100 \%)$ & $265(100 \%)$ & \\
\hline \multicolumn{4}{|c|}{ Phase of medication administration } \\
\hline Pre-administration & $86(57.7 \%)$ & $0(0.0 \%)$ & $<0.001$ \\
\hline Administration & $61(40.9 \%)$ & $1(0.4 \%)$ & \\
\hline Post-administration & $2(1.3 \%)$ & $0(0.0)$ & \\
\hline Total & $149(100 \%)$ & $265(100 \%)$ & \\
\hline \multicolumn{4}{|l|}{ Age } \\
\hline$<26$ years & $12(8.1 \%)$ & $9(3.4 \%)$ & 0.046 \\
\hline $26-30$ years & $121(81.2 \%)$ & $230(86.8 \%)$ & \\
\hline $31-40$ years & $14(9.4 \%)$ & $26(9.8 \%)$ & \\
\hline$>40$ years & $2(1.3 \%)$ & $0(0.0 \%)$ & \\
\hline Total & $149(100 \%)$ & $265(100 \%)$ & \\
\hline \multicolumn{4}{|l|}{ Gender } \\
\hline Male & $22(14.8 \%)$ & $51(19.2 \%)$ & 0.284 \\
\hline Female & $127(85.2 \%)$ & $214(80.8)$ & \\
\hline Total & $149(100 \%)$ & $265(100 \%)$ & \\
\hline \multicolumn{4}{|l|}{ Marital status } \\
\hline Single & $12(8.1 \%)$ & $9(3.4 \%)$ & 0.059 \\
\hline Married & $137(91.9 \%)$ & $258(96.6 \%)$ & \\
\hline Total & $149(100 \%)$ & $265(100 \%)$ & \\
\hline \multicolumn{4}{|l|}{ Education level } \\
\hline Diploma & $131(87.9 \%)$ & $208(78.5 \%)$ & 0.044 \\
\hline Bachelor & $15(10.1 \%)$ & $42(15.8 \%)$ & \\
\hline Masters & $3(2.0 \%)$ & $15(5.7 \%)$ & \\
\hline Total & $149(100 \%)$ & $265(100 \%)$ & \\
\hline \multicolumn{4}{|c|}{ Professional experience } \\
\hline$<6$ years & $20(13.4 \%)$ & $16(6.0 \%)$ & 0.031 \\
\hline $6-10$ years & $96(64.4 \%)$ & $176(66.4 \%)$ & \\
\hline$>10$ years & $33(22.1 \%)$ & $73(27.5 \%)$ & \\
\hline Total & $149(100 \%)$ & $265(100 \%)$ & \\
\hline \multicolumn{4}{|c|}{ Nurses' perception to WIs risks to cause medication administration error } \\
\hline Not applicable & $1(0.7 \%)$ & $260(98.1 \%)$ & $<0.001$ \\
\hline $0-3$ & $134(89.9 \%)$ & $5(1.9 \%)$ & \\
\hline $4-7$ & $14(9.4 \%)$ & $0(0.0 \%)$ & \\
\hline Total & $149(100 \%)$ & $265(100 \%)$ & \\
\hline
\end{tabular}


Table. 4. Multivariate analysis of the factors associated with interruption occurrence

\begin{tabular}{lll}
\hline Variables & OR (CI 95\%) & P-value \\
\hline Shift of Day & $4.10^{-63}(0.000-9.815)$ & 0.038 \\
Time of medication round & $1.10^{22}(0.000-6.122)$ & 0.061 \\
Duration of interruption & $3.10^{-109}\left(3.10^{-109}-3.10-^{109}\right)$ & 0.001 \\
Phase of medication administration & $2.10^{9}(0.000-4.503$ & 0.102 \\
Age & $6.10^{8}(0.000-3.455)$ & 0.201 \\
Education status (in nursing) & $7.10^{-10}(0.000-1.823)$ & 1 \\
Professional experience (in nursing) & $7.10^{-8}(0.000-2.918)$ & 0.295 \\
Nurses perception to WIs risks to cause medication & $1.10^{-8}(0.000-3.301)$ & 0.224 \\
administration error & & \\
\hline
\end{tabular}

